\title{
Streptococcus vestibularis
}

National Cancer Institute

\section{Source}

National Cancer Institute. Streptococcus vestibularis. NCI Thesaurus. Code C86810.

A species of facultatively anaerobic, Gram positive, cocci shaped bacteria in the phylum

Firmicutes. This species is alpha hemolytic, alpha glucosidase and urease positive and negative for catalase and arginine deaminase. It is able to ferment lactose but not mannitol, sorbitol, inulin, or raffinose. S. vestibularis is found in the human oral cavity and is not a known human pathogen. 